\title{
Imaginary 'Homeland' and Constitution of a Collective Identity in Diasporic Experiences: An Analysis of The Hundred Secret Senses by Amy Tan
}

\author{
Naeimeh Tabatabaei Lotfi \\ PhD Student of Islamic Azad University, Central Tehran Branch and \\ The Faculty Member of Islamic Azad University, Shahr-e-Qods Branch, Department of English Translation \\ N.tabatabaei@shahryariau.ac.ir \\ Shideh Ahmadzadeh Heravi \\ Associate Professor of English Literature, Faculty of Letters and Human Sciences \\ Shahid Beheshti University \\ Sheed9@gmail.com \\ Jalal Sokhanvar \\ Professor of English Literature, Faculty of Letters and Human Sciences \\ Shahid Beheshti University \\ Nakhoslaj@gmail.com
}

\author{
Doi:10.5901/mjss.2013.v4n14p385
}

\section{Abstract}

In most contemporary memory narratives that deal with diasporic experiences, the concept of 'home' becomes a semiotic site, in which the fluctuating images of past are in a perpetual conflict to make sense. Absence of home generates a rich ground of creativity for migratory subjects to construct an imaginary homeland, based on their present contingent socio- cultural paradigms. Formulation of fluxing, disintegrated sets of imagery of native land would transcend the national geographical boundaries; thus, a new communal identity is constructed amongst migrant communities, which is fashioned by a universal, humane sense of belonging; generally, it is a diasporic individuality that is liberated from absolute national prejudices. In diasporic portrayal of remote homeland, unlike the exilic mystified or stigmatized presentation of precedent, 'home' is constructed by creative innovatory, progressive interaction of past, present and future to gratify the social and individual demands. Usually, diasporic picture of home is exposed to a conscious strategy of oblivion; whereas, in the case of exilic subjects, there is a rigidified image of homeland. This would intensify the proliferation of falsified, invented picturing of home, in migration genre. These pictures are the product of a confused sense of moral commitment to preserve national heritage and a desire to be part of the dominant host culture. The present essay seeks to explore the heterogeneous procedure of constitution of collective identity in Amy Tan's The Hundred Secret Senses, based on the artistic representation of homeland. This fabricated pristine, identity defies the national borders and enjoys a certain amount of autonomy from established definitions of homeland, which are geographical- bound.

Keywords: Amy Tan-Collective Identity- Diaspora- Homeland- Migration Genre

\section{Introduction}

As a newly found literary genre, migration fiction has enjoyed diverse and heterogeneous sets of principles that are regarded as its distinguishing marks. Most of migrant narratives involve a nostalgic autobiographical representation of past, in form of sharing memories. These memories are not a pure embodiment of past, but they are fluctuating portray of memories which are modified, in order to make sense and suit the present conditions of the experiencing agent, eventually. Depictions of homeland generate an immense part of regretful recalled images, by migrants. As memories have a great effect on the process of construction of identity among individuals, the remembered images of homeland will design a collective sense of identity among immigrants; although, this collective identity is not a homogeneous and integrated national one, but it provides a feeling of belonging and affiliation for migratory subjects. Accounts of past are utilized as a communal instrument for sharing the suffering of marginalized groups such as women, to diminish the loneliness and alienation, in a foreign context. The main focus of this study is exploring the discursive disposition of 
representation of homeland, in generating a unique and distinctive mark, in the context of migration that differs with other contexts of recalling, by sharing autobiographical stories of home, by marginalized groups, such as women.

Mystifying and glorifying accounts of past, about motherland, are common in migration writings, since, location of a person plays a major role, in fabrication of the concept of identity, in his /her life. In this sense, home becomes a transcendental code to be reproduced over and over again, by subjective interplay of meanings. There are many other reasons to recall bygone events with a nostalgic feeling, beside sense of belonging to a certain geographical place. One of them could be the sense of obligatory responsibility felt by immigrants, toward their homeland and their national heritage. In this case, recalling memory transforms into a responsibility and ignoring it may endanger the true national status of immigrants, among their society. In diasporic models of recalling reminiscences of past, the notion of home is the crucial integrating concept that bestows a shared ground of coalition, for immigrant communities. However, because of the heterogeneous nature of remembering patterns, among migrant groups, there would be numerous amounts of conflicts, in establishing an authentic portrait of native land. Scrutinizing the irregular diasporic images of homeland is logically connected to analyzing the nature of immigrant narratives that are the core element of constitution of a collective identity, among migrant populations.

This essay seeks to investigate the complex procedure of construction of a collective identity by diasporic communities, in The Hundred Secret Senses by Amy Tan; this communal identity is, essentially, fashioned by reproducing fictionalized epitomes of homeland, through fictionalization. To achieve the main goal of this research, the features of migration literature that are established by the notion of homeland are explored; afterward, Amy Tan's novel is examined for traces of a collective identity, articulated by fictionalized pictures of motherland that are portrayed for second and third generations of migrants, by their parent's narratives. Since Amy Tan is a migrant novelist, the mode and the quality of presentation of an invented picture of her homeland is highly inspired by diasporic experiences of the writer. There are certified, unique trends of recalling past, in texts of migrant writers, associated with the issue of foundation of identity, based on portraits of ancestral homeland. Scrutinizing disparate strategies of portrayal of home is the true manifestation of their socio-cultural background.

This research is dedicated to surveying the undeniable impact of the notion of home, in inventing imaginary depictions of past and a cultural reading of the meaning of home for migrant population, in diasporic context, is selected as the major analytical approach of this study. The main sources of this study are provided by library research and electronic resources, about the interdisciplinary discourse of recalling precedent that leads to generating pioneering portraits of homeland, among migrant novelists.

\section{Theory (Migration Genre)}

In this section, the miscellaneous spirit of accounts by immigrants, as they are documented and dependant, intensively, based on the concept of memories of native land and migration is explored. One of the features of migrant genre is its involvement with the concept of homeland, nationality and identity. It seems that most of the migration narratives deal with the concept of origin, in order to mold a shared sense of belonging and identity, in diasporic societies. The strife for preserving memories of homeland may result in generating unauthentic precedent imagery, amongst migrants; this obsessive desire to mystify the imagined origin may lead to fictionalization. There might be disparate reasons for dislocation of migrant communities, but the unifying quest for origin results, in creative ground-breaking narrative strategies, amid migrant authors. However, it is the task of memory to grant access to remote history; since, it is a fluctuating field of contemplation and everlasting reconstruction, the product would be a contingent mixture of yearning and nostalgia, embedded, in the form of conscious and unconscious reminiscences of past. Additionally, national tendencies and patriotic prejudices are among the most significant factors, in formulating the notion of 'self' in a certain migrant society. These issues, equally, are accountable in containing or suppressing a definite variety of portrayed memories of imagined homeland. Currently, the trends of diaspora memory studies are moving toward displaying socially constructed images of past; imaginary, articulated embodiments of home supply the raw material for these fluctuating descriptions. Nonetheless, these descriptions are, drastically, ascertained by reminiscences of homeland that are highly discursive, uneven and irregular. Since all aspects of migration are extremely affected by the notion of native land, the texts of such novelists are marked by a moral and national compulsion to articulate a mutual sense of identity, among the characters, by concentrating on the issue of home. No matter if this concern about homeland is based on a mandatory dislocation of the migrant person or a desired one, the outcome of this diasporic presentation of motherland is incongruent. As a result, there are distinctive features of mentioned documents, which are related to the notion of formation of identity, by collective memories, mostly fashioned about the imagined reminiscences of homeland. However, 
because of the disparate nature of these memories, the national chauvinistic trends have faded, gradually, in this process and the fashioned individuality appears to convert into a more flexible diasporic identity that enjoys a certified amount of autonomy from national prejudices.

According to Richard Roberts the main incentive for such a performance is that, "history and memory are intimately linked to places. People move and they stay put. In each case, people produce history about the places they inhabit or that they used to inhabit" (520). Essentially, the plots of migration tales are developed by the act of recalling past. This formulates a fertile ground of constitution of migratory identity, based on the cultural paradigms of homeland, as well as conventions of the host country, since the interdisciplinary patterns of recalling are governed by the concept of place. Moreover, many migrant narrators perceive the duty of remembering as a "moral obligation to ancestors, parents, and to the children and grandchildren who will survive them" (Rogers 126). The feeling of moral commitment toward national heritage is responsible for constitution of a national identity, among the next generation of migrant population.

The constituted identity enjoys a certain quality of discontinuity and heterogeneity. Thus, the collective identity of dislocated migrants is molded by the falsified pictures of homeland, generated by familial memory narratives. These texts are mostly written with a mystified perspective toward homeland and implicate mythical elements in their structure. The result of such efforts is clear; that is constructing a shared sense of individuality, among immigrants who experience nostalgic sensations toward home. Nevertheless, the articulated identity moves beyond the national boundaries and represents a more humane version of life. The portrayed images are usually fragmented and non-authentic, but they claim authenticity by installation of historical data. This may originate from the fact that Tan, like many other migrant novelists, desires to generate an impeccable version of truth about her past, thus, create a sense of communal identity despite diversity. Although the researcher is well aware of the complicated discursive definition of national identity in the multi- national recent societies, it appears that there is an impulse to contain in the contingent heterogeneous definitions of Chinese identity, among characters of Tan's novel that leads to foundation of a multi-dimensional Chinese- ness, based on the notion of homeland and diverse patterns of connectedness to it.

According to Gabriele Rosenthal, "narratives of experienced events refer both to the current life and to the past experience. Just as past is constituted out of present and the anticipated future, so present arises out of past and the future. In this way biographical narratives provide information on the narrator's present as well as about his/her past and perspectives for the future" (11). In this case, the migration narratives, based on the fragmentary imagery of the place of dislocation or 'homeland' develop into the discipline of subjective interpretations and elucidation of history; thus, it produces a diverse heterogeneous quality, in the imaginary perception of second and third generation of migrant societies who rely on their parent's narratives, about their ancestral remote native lands, vitally.

As most migrant communities might feel second class citizens or 'Other', in their new host cultural society, their reproduction of their imagined homelands is a kind of a defense mechanism to preserve their selfness, a way to integrate a plausible sense of identity; not to forget that this sense of nostalgic production of past is a mixture of national prejudice and a sense of detachment to dissolve, in the host culture. It is crucial to remember that this newly constructed identity, influenced by numerous factors such as social class and family background of the immigrant society, is a heterogeneous entity that modifies itself, in different patterns.

On the other hand, memories of past which are presented, in the form of evocative narratives of home, are instrumented as a means of breaking the imposed silence, for marginalized minorities,

Narratives can provide means for a 'counter-story' for a minority or an oppressed group, in which some of the central concepts of a dominating discourse can be appropriated and given new meaning, however, those more powerful 'representatives' of a marginalized group can exert a discursive influence in seeking to define how their groups should be represented. (Eyerman 162-3)

Unfortunately, the power relations will determine the meaning of these newly produced narratives; since, even among migrant communities, there is an unwritten hierarchical social stratification that controls the proliferation of meanings, in a certain social context. This generates many controversial and even contradictory epitomes of precedent, amid migrants which strive to be observed and heard.

On the whole, it seems that despite the discursiveness of reproduced images of homeland, there is a strong inclination amongst migrants to conjure up a collective and common portrayal of their past. This is disputed by different versions of counter- memories, about past and specially homeland, by socially and politically marginalized groups of immigrants, such as women and exiles; thus, a number of heterogeneous memory-based versions of accounts which surprisingly appears to fashion an integrated cultural realm, by containing and unifying different renderings of memories, are fabricated. The next section of this research is dedicated to scrutinizing the vital role of homeland, in migration narratives. 


\subsection{Homeland}

In diasporic experiences, the notion of origin is closely correlated to the innovatory portraits of home that are conjured up, by the first generation of immigrant communities or media. These wistful descriptions, whether positive or negative, are directed, in generating a communal image of home; despite the fact that, there are vivid discrepancies, in the temperament of portrayed images, due to different motives of migration. Frequently, in the case of exilic migrant communities, there is a nostalgic and positive perspective toward imagination of home that is accompanied with rejecting the host culture and assimilation with it. However, the voluntary migrants present diverse sets of mixed imagery of homeland that is associated with their intentional will to contain in the host culture; thus, their portrayed images are fragmentary images that strive to be in line with their mimetic endeavors to be a part of the host culture. One of the presumptions of this research is that memory, as one of the pivotal factors that engenders an opportunity for immigrants to illustrate their imaginary homelands for next generation, plays a key role in granting the raw material, for innovative pictures of native land. Hence, memory is over emphasized, in the procedure of picturing façade birthplace, functionally.

Since memory has a substantial role in bestowing access to remote past, images of homeland are hugely dependent on the personal motifs, social patterns and cultural paradigms of remembering agent. According to Maurice Halbwachs, in On Collective Memory, the fact that memory is "structured by social arrangements" means that memory is articulated, according to realities of the present and in a certain social context (38). This again highlights the magnitude of homeland and belonging to a certain geographical place, in the process of recalling. For immigrants who are away from their homelands, each and every object or image may trigger memory and stimulate a nostalgic feeling about it; however, since it is not in the social context where it was articulated, the effect would be wistful and assorted. Narratives of past are not only shaped by the imagination and interpretation of the diasporic experiencing agents, but they are also fashioned by multi- factorial constituents, such as the perception of the host culture and dominant imagery presentation of a certain migrant population, in the media. Astonishingly, the reputed schematic perception of readers of a literary text would be re-fashioned, after reading a certain text. This means that the identities of not only migrant communities, but also the readers of a literary text are exposed to re-fabrication and flex. The place or the geographical root of one person has an undetectable effect on the true insight of the notion of 'self'. In a particular detached community, there are always a trace of similitude and uniformity in these images, although the social, financial and racial statues of recalling agents differ. These similar resemblances of home would result in constitution of a shared communal identity, between migrant societies that comprises a unique quality, despite miscellany.

According to Homi K. Bhabha, historical accounts are responsible for spawning "imaginative counter discourse" in society; therefore they offer a prospect for different social classes to experience varieties of identities. In migration literature, narratives gain a remarkable significance, in which identity questions prevail. The procedures of fabrication of identity might be contingent and complicated, in the case of migrants. New acquired identities, mainly affected by the socio-cultural settlements of the host country, are in a perpetual struggle to dominate the national identity. However, this diasporic national identity is subject to diversity and contingency, itself. Some critics suggest the possibility of existence of multiple types of identities in individuals, based on different social situations. On the other hand, Homi Bhabha criticizes the idea of having 'multiple identities', because it means an illusionary distinct sets of identities, which must be selected and acquired by individuals. He argues that while articulation of identity might be allied with negotiating heterogeneous identifications in the personal levels, the whole process is an ambivalent one. He replaces the term 'multiple identities' with "the doubleness of identity". He suggests that double identity is not two identities, but it is "the negotiated iterability of identity, its constant repetition, revision, relocation, so that no repetition is the same as the preceding one" (12). Denouncing the existence of multiple identities would, clearly, suggest the flexibility and dynamicity of the process of formation of identity. In the case of immigrants, this establishment is more exigent, because the miscellaneous diasporic identities are, perpetually, in conflict. This proves that the procedure of construction of identity that is considered to be a complex one appears to be more challenging, for migrant communities who are in a continual exertion to build an identity that would suit their diasporic status, as well as their national one.

Stories of past, which mystify native land, are widely conventional in contemporary migration literature; though there are many other cases that stigmatize homeland and admonish its dominant values and status. According to Roberts, the main reason for such an act is that, "history and memory are intimately linked to places. People move and they stay put. In each case, people produce history about the places they inhabit or that they used to inhabit" (520). There is countless number of other reasons to recall past with a regretful feeling, beside sense of belonging. One of them might, perhaps, be the sense of responsibility that is felt by immigrants toward their homeland and ancestors. Many narrators feel a commitment to remember their national history; there is always "a moral obligation to ancestors, parents, 
and to the children and grandchildren who will survive them" (Rogers 126). In this case, remembrance converts into an ethical responsibility and ignoring it might endanger the true status of immigrants, among their society. The representation of the felt moral commitment is exhibited, in the form of urgency, to recall the exact conditions of motherland and transfer it to the next generation. However, faithful recalling of history and its details is unattainable, as diasporic experiences leave their everlasting marks on the paradigms of remembrance that are based on egocentric desires of recalling agents.

In "Diaspora and Cultural Memory", Anh Hua examines the patterns of remembrance, in migrant communities. She thinks that not all the diasporic groups recall homeland with a feeling of nostalgia; for instance, women remember it with a desire to break the masculine power of their previous cultural and social status. Thus, they construct a new set of norms to live in their new home (188). In this regards, memories of homeland turn into the contestable issue of contemplation that would be used as a weapon to defy patriarchal laws. Conversely, there is always an urge to be contained, in the host culture; this creates other types of challenging oppressions such as racial or class suppression. Women launch to compensate for the feeling of loneliness, by narrating stories about 'home' for their children who are alienated from their ancestral heritage, but since memory could be displayed in distinct methods, narratives differ, each time, based on present reality of migrant 's life. Hua suggests that within diasporic studies "memory can become a strategy for social justice, by recalling the forgotten or suppressed to bear witness, yet it is a strategy that requires reading 'the past as conflictual, evidence as problematic, all questions as suspect"'(198). The representation of contingent descriptions of homeland by multi-cultural migrant communities and the media presentation of a certain country disputes the authenticity of depicted images and generates a chaos, in the mind of children. They are caught between the desires for an unseen paradise, with its own cultural paradigms and an urge to assimilate completely with the cultural norms of their new home.

This strengthens the assumption that the meaning of 'home' is not a fixed entity and alters based on the current conditions of diasporic agents who are struggling with new internal or external barriers, in their new habitats. Mohamed Hafezi states that the meaning of 'home' is different for migrants who have left their countries, because of different intentions. However, this dislocation, whether by force or voluntarily, becomes an appropriate stance for literary innovation for many novelists, "for many exilic writers, nevertheless, memory of home become the ground of creativity and invention exactly because of its remoteness, intangibility and inaccessibility" (135). He distinguishes two types of categories for the concept of home. He labels the first concept a geographical concept which is related to physical borderlines; this is associated with the ones who are living in another country, because they are forced to, i.e. exiles; the other concept of home is called a "diasporic home" and is experienced by the immigrants who are willingly living in another country and wish to be a part of that society, completely, one day, "while an exilic approach to home is based on national boundaries, in a diasporic approach, home is not linked to a certain physical space; it is rather transnational in character and is a constructed space in the present through contacts, memories and activities"(8). In this case, the imaginary concept of home, for most of migrants, is not rigidified by the geographic definition of it; home is assembled by creative interaction of past, present and future. Like the distance that exile imposes on a writing subject, narrators of migrant genre also view the present, in terms of its distance and detachment from past and future. The immigrant genre is also marked by a curiously detached reading of the experience of 'homelessness' which is compensated for, by an excessive use of the metaphor of luggage, both spiritual and material (8). For exilic subjects, there is always a desired hope to return, promptly, to the remote invented paradise, labeled as homeland. Frequently, even if they return, one day, they would be disappointed to find out that their imagined portrait is far gloomier than they dreamed of.

Hafezi uses the ideas of Dean Franco in, "Re-placing the Border in Ethnic American Literature", in order to define separate definitions for exilic and diasporic ethics. An ethics of exile is characterized by the persistence of memory which results in rigidification of identity, "an exilic identity is an identity constructed away from home through the mediation of a will to memory... it is mimetic (in the sense that it aims at representing the 'original' identity)" (146). Nevertheless, it is exposed to the diasporic resourceful creation of desired homeland; thus, it is still open to various modifications that are rooted in the social, racial and financial status of the exilic subjects. This would determine the heterogeneous pictures which are represented by exilic narrators.

In contrast, the diasporic experience is characterized by a "weakening of memory and a dispersion and rupture of identity, twilight of oblivion. Therefore, an ethics of exile is conservative, while an ethics of diaspora is progressive, i.e. open to the possibility of change and non-mimetic" (147). This clearly indicates the playful creativity of migrant authors, in picturing their homeland. To comprehend the complexity of the rendered images, entirely, the diasporic experiences and subjective interpretations of the experiencing subjects must be adjoined in this procedure. This designs multihued images of home. 
Abdul. R. Janmohamed suggests that different ethics of exile and diasporic migration are based on the idea of 'absence of homeland'. He believes that because the exilic individual is forced to leave, there is a sense of indifference to the values and socio-cultural paradigms of the host culture; therefore, the migrants choose to "live in a context that is least inhospitable, most like home" (446). This is the eminent trait of exilic genre. It is depicted in the wistful, nostalgic narratives about motherland, by exilic writers. Exilic accounts, usually, presents an Eden-like place that would gratify the dreadful alienation of dislocated people. There is always a flicker of hope to return, one day and this ensures the regretful temperament of narratives about homeland. For migrants who have left their homes for other various reasons such as financial reasons or educational promotions, the story diverges, there is a "voluntary desire to become a full- fledged subject of the new society" (446). Thus, a migrant, willingly, accepts the collective subjectivity of the host country and confirms its cultural paradigms. Lack of external forces, such as exile, breeds a sense of sovereignty, in picturing the desired native land for immigrants that would result in formation of a different subjectivity. However, this assorted individuality might jeopardize the norms of national identity; thus, these newly formulated identities are rejected by radical national movements. Nevertheless, even these innovative identities, are subject to irregularity and heterogeneity. Immigrant communities are reinforced to conserve their national heritage; equally, they are pressured by the cultural hegemony of the host country to assimilate with dominant cultural conventions. Consequently, a troubled identity sets up that rejects the established norms of society. These heterogeneous, hybrid identities introduce novel forms of subjectivities that vindicate adjusting and appropriating pictures of homeland, with the present demands of migrants, in diasporic contexts.

Obviously, diasporic experiences are distinctive for migrant women. Most of them are exposed to not only patriarchal forces of their culture, but they are also threatened by the hostile environment of their new habitats. This hostility is marked by explicit and even implicit racial discriminations that generate a sense of homesickness. In this context, memory, as the safe means of narrating history, becomes a defense mechanism for migrant women who are usually illiterate and have a little knowledge about the language of their newly- designated domiciles. Recalling memories is directly influenced by the previous and present social, racial status of narrators; therefore, divergent mixtures of memories are produced that are full of contradictions and paradoxes. Vijay Agnew in, Diaspora, Memory and Identity: a Search for Home (2005), discusses the existence of contingent quality of memories of homeland, among migrant population. Agnew suggests that the notion of 'home' plays a considerable part in the process of fashioning the identity of migrant communities. Agnew argues that, in diasporic context, identities are fabricated outside the ambits of race, nationality and class stratifications,

The consciousness and identity of diasporic individuals may focus on their attachment to the symbols of their ethnicity, and they may continue to feel emotionally invested in the 'homeland'. Yet such attachment and sentiments are experienced simultaneously with their involvement and participation in the social, economic, cultural, and political allegiances to their homes in diaspora. (14)

This clarifies that a flexible identity is experienced by immigrants in the host country that is highly influenced by carefully- structured images of 'home'. Usually past is exorcised by the means of recalling memories that supply diasporic individuals with blurred and sometimes falsified images of motherland. Whatever they do, they are individuals who seem to be shadow-like creatures and if this is so, one can easily choose his own favorite epitome of home. Not to forget that like many other aspects, in diasporic experiences, there is numerous amount of perplexity and confusion about the authenticity of presented, preceding imagery. This bewilderment is merged with a feeling of a desire to belong to a certain fixed home and having authentic rigidified memories of it; this is, paradoxically, accompanied with a passionate aspiration to be an active participant of the new diasporic world.

As mentioned, most of migrant women experience a double amount of marginality, loss and pain in their new diasporic habitats, but they are supposed to tolerate the harsh conditions of life, in order to survive and unite their families who rely on them for emotional and financial support. Vijay Agnew elaborates on the migrants' effort to establish a collective identity that surpasses the geographical boundaries, based on their contingent memories of their homeland. Migrants, who are displaced from their homes, are forced to modify and appropriate their cultural and traditional perspectives, to be accepted, partially, in the host country. Here, memories play a noteworthy role in reconstructing a new identity, by the means of fictional accounts and autobiographies about home. However, the validity of recorded memories is contested by official, documented history of a nation. Their incapability in speaking the language of the host culture intensifies the racial and gender discriminations imposed on them. This heaps on their responsibility, in transferring true pictures of native land to the next generation. This is blocked with their motherly affections, toward their children, to be a genuine part of the host culture, with all its potential opportunities and privileges. Usually, mothers encourage their children to assimilate with socio-cultural paradigms of the host culture; hoping that one day, they are 
accepted as a genuine subject of the host country.

However, memory's of home is an important instrument for those migrants who have left, because of political or financial reasons; without a complete sense of detachment, there is not a full desire to be a fully integrated subject, in the culture of the country they have entered. At the same time, there is an obligation to remember or forget certain kind of memories. This makes memory a transient field of creativity and imagination, in which fact and fantasy are mingled to form an ever-changing history for migrants. Consequently, divergent sets of images of homeland are reproduced by migrant communities. Desire to be an authentic part of the host culture and the natural quest of origin will create a discomfited individuality, in migrants. This could be depicted in the form of migration narratives, with their distinguishing traits; in the case of women, these narratives are strategies to ensure a sense of self- affirmation, something that most of them lacked in their home country. Next section would explore the fundamental task of the notion of home, in forming a communal identity, among migrant population.

\subsection{Absence of 'Home', Construction of a Collective Identity}

As mentioned in the previous section, the aim of strategy of sharing preceding memories, about ancestral homeland, is uniting the immigrant families, as well as helping parents to transmit national identity, to their children. However, it is necessary to bear it in mind that this identity enjoys a certain amount of heterogeneity and multiplicity. The major intent is that, in the process of recalling memories of birthplace, a collective identity is also constructed, as well as individual identity of diasporic members. Collective identity could be discriminated from individual identity, by its communal procedures, in articulation of shared identities that coalesces migrant communities. It is defined as recollections of a shared past's reminiscences, based upon a "common heritage" by Ron Eyerman. The collective memory has the power to "orient a group, providing the temporal and cognitive map"; this helps them to create a sense of identity by unifying "the group through time and over space by providing a narrative frame, a collective story, which locates the individual and his and her biography within it" (161). Thus, a common identity is, mutually, shared by a group, while they enjoy a specific amount of autonomy, in creation of their own narratives, as individuals. The substantial crux of articulation of collective identity, through memories of motherland, is that narratives of a group may transcend time and place. As a result, they transform into specified kinds of products such as myths, legends and ideologies. Shared experiences of a nation through ages, whether good or bad, will be the ground of a nation's narratives. These stories fabricate the common identity of a nation and they are the true manifestations of a national strife to survive, throughout history. Modifications and fictionalizations are the natural product of the process of recalling; memory's performance, in society, is determined by cultural paradigms. Because this operation is a reciprocal activity, individual recalling trends would refashion the socio- cultural prototypes, simultaneously. Here, the fictionalized descriptions of homeland play a crucial function, in determining the quality of the constituted narratives.

As this collective identity is related to the values and traditions of a specific society, it is allied with the concept of culture and is entitled 'cultural Identity' by Stuart Hall. He calls the cultural identity a "shared culture, a sort of collective 'one true self,' hiding inside the many other, more superficial or artificially imposed 'selves,' which people with a shared history and ancestry hold in common"(234 ). In this model, shared history and cultural codes form a frame of reference, a feeling of belonging for a group of people; although, even this identity is not static and stable. It is in a continuous flux and fluctuation, since it is dependent on a complex network of history, power and culture. Continually, it is shaped and reshaped by different factors, "far from being grounded in mere 'recovery' of the past, which is waiting to be found, and which when found, will secure our sense of ourselves into eternity, identities are the names we give to the different ways we are positioned by, and position ourselves within, the narratives of the past" (236). Accordingly, these cultural identities are the matter of appropriation and alteration; they gratify the egocentric demands of an individual, in a particular social context. In migration genre, there are traces of strife for articulation of a collective identity amongst the characters, based on ethics of home, along with formation of independent individual identities, usually based on morals of the host culture. This point marks the paradoxical quality of migration narratives, about homeland. The next section of this research surveys the utilization of ethics of domicile, in Amy Tan's The Hundred Secret Senses that aims at constitution of a shared identity among characters, through the erratic images of home, presented by parent's narratives, to their culturally- estranged children.

\section{Amy Tan, Home and Politics of Construction of a Collective Identity}

Constitution of identity, in texts of migrant writers who are dislocated from their homelands, for distinctive rationales, is 
usually based on reproduction of bygone reminiscences, creating a unique narrative effect. Accordingly, the migration literature becomes the field of continuous formation of not only personal, but also collective identity. Tan, who is one of the second generations of immigrant writers, smartly, implicate the morals of native land to generate a collective identity, among her culturally-alienated characters, through the contradictory embodiments of homeland, represented by their parents. In her novel, home becomes the site of conflict and comfort, simultaneously. It is where all the suffering is terminated by creating a sense of communal identity, among the culturally isolated characters. In describing home, often, there are traces of pain and suffering of mothers and confusion of daughters, in accepting China as homeland, that coexist with a lamentation for re- union and becoming one with the exotic and magical origin. The structured individualism, in migrants, is closely associated with the idea of homeland; though, it is not based on realities of home; usually, it is an impostor formation of it that is a rich blend of fantasy and fact, highly dependent on the present conditions of immigrants. This section of essay is an attempt to study the process of formation of identity, in the characters of one the most eminent novels of Tan, The Hundred Secret Senses, which enjoys a certain amount of collectiveness of identity, despite diversity and contingency of diasporic individualities. The researcher intends to suggest that, in a diasporic context, depictions of past, successfully, shape a sense of shared identity amongst different characters of the novel; not to forget that this fashioned identity is beyond the national boundaries and is expanded in a universal scale. This is displayed by a return to the host country, which demonstrates the tendency to be a part of the host culture. This ensures the strategy of oblivion of some parts of home narratives, in order to preserve the internal, mental integrity of the characters.

The Hundred Secret Senses starts with cultural codes that are unique to the exotic China. The presence of Kwan as resemblance of China disturbs the mind of the American born Olivia who is scared, and at the same time fascinated by the stories and strange abilities of her sister who claims to observe the ghosts of dead people. Kwan can also cure people by touching them; she is also capable of telling them about their past and future; and this connection with past, as well as future, makes Kwan as a symbol of a desire for existence of a collective, shared identity. This communal identity is transferred, most of the times, by recalling past memories, which results in redemption of characters. The story ends with a trip to China, as a symbolic return to the origin; in this journey, the major character is reunited with her husband, Simon. Amy Tan's mothers and in the case of this story, the step sister, who share their memories with their American born daughters try to define a sense of what it means to be an authentic Chinese; their stories is a way to construct a collective Chinese identity, in their daughters. It initiates with the haunting ghosts who come and visit Kwan who has "Yin Eyes" and it means "she sees those who have died and now dwell in the world of Yin, ghosts...." (3). This line emphasizes the haunting nature of past and its recurrent return to posses what belongs to it. The fact is that the existence of Kwan was also revealed as an enigma of past when the father of the family was dying, in the hospital. Returning Kwan is the last wish of a dying man who asks his wife to claim his daughter to be brought to America, from China. This also implies the similarity of Kwan and collective memory as both of them are brought to existence, when death endangers the individual. Just like summoning the forgotten memory of home, Kwan comes to America to bring the reminiscences of 'Home' to an alienated diasporic community. The most significant point that likens Kwan to collective Chinese memory is that she asserts to have multiple life spans in past, to which she is still connected to. Kwan even criticizes Americans for not having a respect toward precedents and thinks that Chinese memory is something which travels through time, but for a westerner, things are different, "Americans have short memories too, I think. No respect for history, only what's popular" (360). The influence of collective identity, on life and beliefs of diasporic individuals, is so sturdy that Olivia converts into a person who thinks and dreams as Chinese. In The Hundred Secret Senses, Kwan may perhaps be the representative of the existence of collective Chinese memory who travels to America from China in order to awaken the sense of Chinese identity in characters of the novel, "she pushed her Chinese secrets into my brain and changed how I thought about the world. Soon I was even having nightmares in Chinese" (13). The effect of native land and the sense of belonging are elaborated by Lisa Lowe who suggests the multi-factorial patterns of transmission of culture via the concept of homeland. China becomes the core entity that formulates the identity of characters and structures their relations with outside world.

In her famous essay, Lisa Lowe investigates the process of transmission of culture as one of the factors of construction of identity and suggests that the diversity of immigrant societies would result in heterogeneous dimensions of experiences. Lowe suggests,

By 'heterogeneity' I mean to indicate the existence of differences and differential relationships within a bounded category.... By 'hybridity' I refer to the formation of cultural objects and practices that are produced by the histories of uneven and unsynthetic power relations.... Finally, we might understand 'multiplicity' as designating the ways in which subjects located within social relations.... (138) 
Diverse number of subjectivities and identities are created amongst diasporic individuals of Asian- American communities; this makes distinguishing an authentic cultural feature, an intricate task. This must be considered that, not only the intra- cultural affiliations and discrepancies might exist, that gradually mingle to structure spanking identities, but there is a great amount of inter- cultural mingling among the members of dominant culture and other minorities. The assimilations of the second generation of American born children could be, then, considered an effort to be configured in the dominant discipline that is confronted with the nationalist desires of mothers who try to formulate a communal identity, among the members of their families. Although, according to Lisa Lowe, Chinese ethnic identity, like other identities, is not a rigid, there is a strong penchant, in Tan's novel to reach a shared identity, between the characters. Return to origin, is a sign of negotiation in this novel, despite the fact that there are many major discrepancies in the process of construction of identity, in mothers (or mother figures) and daughters of the novel, based on innovatory picturing of homeland. Morals of home are sacred for mothers who try to transfer it to their multi- identity exposed daughters. This demanding job ends with reconciliations of generations, by constituting a diasporic shared identity among them. Olivia travels to China with Kwan, but returns to her diasporic habitat.

It is suggested, in "The Body as a Medium of Memory", that body may stand as loci for bodily communication of past, "the human body serves as a medium that communicates past experiences, actions, and emotions into the present. It does so in both a passive and an active manner. In other words, the body serves as a symbol, but as a living symbol, one that contributes to the meaning communicated through it" (Steineck 46). Theoretically, if human body is looked upon as the medium for storing emotions, then, it is probable that like every other biological characteristic, which is geneticbond, memories are capable of transmitting genetically to offspring. The magnitude of collective memory, generally about homeland, which spawns a sense of collective, shared identity and its transmission to next generation, in this novel, is represented by another character that is dead. It is only her memories which shape our understanding of her, in the story. Elza, the late lover of Simon, also claimed to have a kind of an intuitive knowledge "that cannot be thought. She said her mother's memories passed from heart to womb and they are now indelibly printed on the walls of her brain" and based on that she believed to have Polish Jews parents who were killed in the war (82). The narrator of the story who sees analogies of this claim and the claims of Kwan rejects the possibility of this biological memory that could be transmitted genetically, about origin; she thinks that maybe Elza has read something about the incidents of war in her head, "you know how people see old photos or movies and later think they were personal memories. Or they have a Déjà vu experience..." (82). The eccentric and mystic stances of connectedness to the origin, by the means of bygone recollection, verifies the impact of root or home, in one's life. This story again ends with a trip to China to complete the circle of collective identity construction; it is celebrated with the birth of a girl who is going to be the next generation of daughter's of China who communicate the heritage of their homeland to next generation. Return to America and giving birth to a girl who is going to grow up in a new habitat is the indication of the point that the articulation of collective Chinese identity is not equal to be a Chinese person, with definite ethics. This identity enjoys certain liberation from established, institutionalized cultural disciplines; thus, it is more like a sense of humane empathy among characters. The involvement of the process of recalling in formation of identity highlights the fact that memory is a cultural-context subject that not only gains meaning in socio-cultural affairs, but it also shapes the cultural paradigms of a society; constitution of identity is one of them. Frequently, the notion of home is the focal point in diasporic patterns of recalling.

Often, the children of Tan's novels, as well as the novel under scrutiny, cannot understand the meanings associated with the stories of their mothers (mother figure), about their ancestral homeland. Therefore, it becomes evident that, without the social context, through only listening to the stories, told by their parents, many secondgeneration of Chinese- Americans acquire only a superficial discernment of Chinese culture; many of them continue to perceive China as a remote and imaginative space, somewhere in the East. As most of the mothers in Tan's novels have immigrated to America, because of the financial problems or tyranny of their social surroundings, there is a sense of exile existence in the United State for them; thus, they try to keep as far as they could from the Western culture. Kwan, the motherly figure of this novel, who struggles to preserve her national identity and transmit it to Olivia, her half- sister, cannot speak English properly. On the other hand, American-born characters, like Olivia, who are all born and educated in America feel to be more American and as they are Chinese-American, the concept of home is a diasporic state for them, where there is not a rigidified assumption about it; it is a transient and contingent remote inventive location. This incomplete knowledge does not only mystify China, but also perplexes the state of the country that they are living. Home and the host country lose their authenticity and convert into an ingenious state of reproduction. In this way, the construction of Chinese identity, in general sense, becomes complete only by a trip to the ancestral land.

Yuan Yuan, in "The Semiotics of China Narratives in the Con /texts of Kingston and Tan" investigates the meaning of China, as a birthplace for characters of the novel. The writer suggests that there are two different contextual stages of 
imagining homeland in these texts, one related to the story of mothers, and the other, related to the present condition of daughters. The contextual quality of the recollected narratives produces dissimilar and sometimes contradictory outcomes in the novels; it highlights the effect of cultural and social agreements, in the process of meaning making. Finally, the writer concludes that 'China narratives' are more than mere traumatic narratives of past; they construct new identities based on generation gap, "eventually, China becomes a semiotic site where culture and identity are fought over, negotiated, displaced, and transformed" (142). This quotation accentuates the conscious effort of migrant writers in picturing the cultural differences, by portrayal of the dynamic images of homeland.

It is suggested that as China narratives are the recollection of parent's past memories, they are open to interpretation and modification,

Their China narratives emerge in the 'other' cultural context informed by a complex process of translation, translocation, and transfiguration of the original experiences in China. In fact, China experiences are generally transfigured into 'China narratives' only after they have lost their reference to China; thus they are related more to the present American situation than to their original context in Chinese society. (142)

This explains the diverse portrayal of China as homeland, in texts of Chinese immigrants. The picturing of the events, in most of the texts, is highly dependent on the accuracy of recollected memories and the context of remembering. This creates distorted and contradictory imagery of China in this novel, where motherland is depicted as the exotic place of redemption and healing and the loss and suffering, simultaneously, by Amy Tan. Transfiguration of home obtains a golden prospect to invent images of China, for estranged diasporic generation.

Yuan believes that the recollection of memories is discursive and related to the context of migrants' lives; the same process is an ingenious one for American born children. This would create a complicated interaction of ideas that would result in a cultural representation of China in Tan's texts, "China becomes a hermeneutic space for articulating identity and difference, a process that governs the cultural and historical reconstitution of the subjects" (142). This quotation emphasizes the cultural establishment of the concept of homeland, by the instrument of memory, which is exceedingly discontinuous and contingent. It is a battlefield where the ideas must be fought over and it is the dominant group who determines the outcome of this struggle, in preserving the semiotic picture of homeland; hence, constructing identity of the characters is governed by the dominant hegemony of migration experience. However, there is a sense of shared appreciation that is celebrated by a reunion with China, in all the novels of Amy Tan. The influential haunting effect of past, related to home, is evident in the stories of Tan and especially in The Hundred Secret Senses, where someone, actually, comes from home to enliven the preceding experiences, for the characters. There is a permanent sensation of confusion about the present and past. For Olivia, this sense of turmoil is followed by a hopeless strife to keep past memories of home, where it belongs to, "for most of my childhood, I had to struggle not to see the world the way Kwan described it. Like her talk about the ghosts."(55). As it was mentioned before, in The Hundred Secret Senses, Kwan could be the true representative of the existence of collective Chinese memory who travels to America from China, in order to awaken the intuitive Chinese identity in characters of the novel, "she pushed her Chinese secrets into my brain and changed how I thought about the world. Soon I was even having nightmares in Chinese" (13). This suggests an unconscious involvement with the concept of homeland and construction of Chinese identity for American born children, but this sensation is accompanied with a feeling of anxiety, for the characters. Olivia's visit to China is a sign of identity negotiation; she experiences a sense of uproar from the moment she reaches there, "My body is already confused as to whether its' day or night" (187). Olivia is disoriented and baffled, due to her diasporic status. The natural felt panic has originated from the presumed cultural similarities; in China this expectation is violated and Olivia feels alienated, in her supposed authentic homeland. Later, this modifies to an impression of calmness and comfort. This reunion with ethics of homeland is the root to terminating the identity puzzlement and foundation of a pristine collective identity, for the major character of the novel.

According to Carol Davis, in "Migratory Subjectivities" issues of home and exile are mingled for women as home transforms into the simultaneous site of comfort and suppression. In the state of migration, "the mystified notion of home and family are removed from their romantic, idealized moorings, to speak of pain, movement difficulty, learning and love in complex ways" (1009). Therefore, home becomes a 'migratory space' for women where there is silence and pain, as well as joy and happiness; it is the manner that most American born children perceive China. When Olivia attempts to visit China, there is a sense of attachment and distance to the mother- land which is mostly shaped by memories of Kwan. It has an inventive existence for her, "We have stumbled on a fabled misty land, half memory, half illusion.... Unspoiled by progress, mired in the past!"(230). Visiting the ancestral land, she eventually becomes an integrated person and not a ghost like Chinese - American, "I feel as if the membrane separating the two halves of my life has finally been shed (230). This proves that 'an apple would not fall far from a tree' and the quest for origin is a strong innate desire. But 
this patriotic sentiment is not a simple one, in the case of migrants who are living in other countries. 'Home' for them is a diasporic, transient location where it is bond with pain and frustration. Like all the other novels of Tan, in this novel, the major character returns to her diasporic habitat. The ancestral home is an invented space that must be preserved in the past; although nothing is the same after visiting it, the prospect and future of the major character lies in her diasporic home.

In the case of third and second migrant generations, the notion of 'home' is always in the state of flux; no clear meaning is defined for it and varied epitomes are presented about it by various migrant groups. These flicks are the product of the present condition and future perspectives of migrants, as well as their desired fantasies about native land. Most parents are willing to raise their children based on the values of host country; this forces them to encourage their children to assimilate the host culture. On the other hand, they always feel a national, moral commitment toward their ancestral heritage. Consequently, the result is constitution of an enormous number of hybrid identities among migrant communities, based on the common interest to preserve the images of motherland. Construction of collective identity is highly attached to the process of recalling; memory is actively engaged in different stages of formulation of identity in personal and collective levels, as a cultural discipline; in the case of diasporic individuals, home plays a pivotal role in fabricating the diasporic identities.

\section{Conclusion}

This study was an attempt to inspect the heterogeneous process of articulation of diasporic identity among immigrants, based on the concept of imaginative pictures of homeland, attained by parents that lead to creation of a shared and collective sense of belonging that defies the national cultural paradigms. It was suggested that the picture of 'home' is a contingent portrayal, which is based on personal discriminatory recollections of bygone memories; it generates numerous fragmentary, innovatory models. The controversial image of home, then, is used to create a homogeneous Chinese subjectivity in immigrants, despite cultural and individual diversities, in Tan's novel; constructed collective identity is built upon a sense of belonging to a universal family, rather than a specified nation. The picturing of ancestral accounts, in most texts of Amy Tan, such as The Hundred Secret Senses, is highly dependent on the accuracy of recollected memories and the context of remembering. This fashions distorted and contradictory images of China, in this novel, where native land becomes the exotic place of redemption and loss, simultaneously. The context- based feature of recalling ensures the multiple versions of China experiences, in which reminiscences of 'home' are modified to match the present demands of individuals. Memory's fallacious tricks would strengthen this process. The outcome is constitution of a shared sense of diasporic identity, among the characters of the novel, which is based on representation of ingenious epitomes of homeland, depicted by memory narratives. This pristine diasporic identity enjoys a certain amount of heterogeneity and contingency, based on the socio-cultural paradigms of home and host country, equally.

\section{References}

Agnew, Vijay. Diaspora, Memory and Identity: a Search for Home. University of Toronto Press, 2005.

Bhabha, Homi. "Representation and the Colonial Text: A Critical Explorations of Some Forms of Mimeticism." in The Theory of Reading. Ed. Frank Gloversmith. Brighton: Harvester, 1984.

Davis, Carol Boyce. "Migratory Subjectiveness" in Ethnic Studies, Post Coloniality and international studies. pp.996-1015.

Eyerman, Ron. "The Past in the Present: Culture and the Transmission of Memory". Acta Sociologica, Vol. 47, No. 2 (Jun. 2004) 1/03/2010, Sage. http://www.jstor.org/stable/4195021

Hafezi, Mohamed. H. "Toward a General Economy of Travel; Identity, Death and memory". Diss. University of Florida. 2004.

Halbwachs, Maurice. On Collective Memory. Ed and Trans. Lewis A. Coser. Chicago: University of Chicago Press, 1992.

Hall, Stuart. "Cultural Identity and Diaspora" in Theorizing Diaspora .Eds. Jana Evans Briziel and Anita Mannur. U.S.A, U.K, Australia: Blackwell, 2003.

Hua, Anh. "Diaspora and Cultural Memory" in Diaspora, Memory and Identity: a Search for Home. Ed. Vijay Agnew. University of Toronto Press, 2005

Janmohamed, Abdul. R. "Worldliness- without World, Homelessness- as Home: Toward Definition of the Secular border intellectual" in A Cultural Studies Reader (History, Theory, Practice) .Eds.

Roberts, Richard. "History and Memory: The Power of Statist Narratives". International Journal of African Historical Studies. Vol. 33, No. 3 (2000), pp. 513- 522. Boston University, African Studies.

Rogers, Kim Lacy. "Lynching Stories: Family and Community Memory in the Mississippi Delta" in Trauma and Life Stories, International Perspective. Eds, Selma Leydesdorff et al. Routledge, 1999.

Rosenthal, Gabriele. "The Narrated Life Story: On the Interrelation Between Experience, Memory and Narration" in Memory, Narrative 
and Knowledge, Representation, Aesthetics and contents. Ed. David Hiles. Huddersfield: University of Huddersfield Press, 2006. Steineck, Christian. "The Body as a Medium of Memory" in Time and Memory. Eds. Jo Alyson Parker et al. The Netherlands: Koninklijke Brill NV, Leiden, 2006.

Tan, Amy. The Hundred Secret Senses. New York: Ivy Book, 1995.

Yuan, Yuan. "The Semiotics of China Narratives in the Con/texts of Kingston and Tan" in Modern Critical Views: Amy Tan. Ed. Harold Bloom. New York: Chelsea House, 2000. 151-164. 